\title{
Electrocardiographic Guidance for the Placement of Gastric Feeding Tubes: A Pediatric Case Series
}

\author{
Michael L Green MD, Brian K Walsh RRT-NPS, Gerhard K Wolf MD, and John H Arnold MD
}

\begin{abstract}
BACKGROUND: The placement of nasal or oral gastric tubes is one of the most frequently performed procedures in critically ill children; tube malposition, particularly in the trachea, is an important complication. Neurally adjusted ventilatory assist (NAVA) ventilation (available only on the Servo-i ventilator, Maquet Critical Care, Solna, Sweden) requires a proprietary-design catheter (Maquet Critical Care, Solna, Sweden) with embedded electrodes that detect the electrical activity of the diaphragm $\left(\mathbf{E A}_{\mathrm{di}}\right)$. The $\mathbf{E A}_{\mathrm{di}}$ catheter has the potential benefit of confirming proper positioning of a gastric catheter, based on and the $\mathrm{EA}_{\mathrm{di}}$ waveforms. METHODS: In a case series study, our multidisciplinary team used $\mathbf{E A}_{\mathrm{di}}$ guidance for immediate, real-time confirmation of proper nasal or oral gastric tube placement in 20 mechanically ventilated pediatric patients who underwent 23 oral or nasal gastric tube placements. The catheters were placed with our standard practice, with the addition of a team member monitoring the $\mathbf{E A}_{\mathrm{di}}$ waveforms. As the tube passes down the esophagus and posterior to the heart, a characteristic $\mathbf{E A}_{\mathrm{di}}$ pattern is identified and the position of the atrial signal confirms correct placement of the gastric tube. If the $\mathbf{E A}_{\mathrm{di}}$ waveforms indicate incorrect placement, the tube is repositioned until the proper $\mathbf{E A}_{\mathrm{di}}$ waveform pattern is obtained. Then proper tube placement is reconfirmed via auscultation over the stomach while air is injected into the catheter, checking the $\mathrm{pH}$ of fluid suctioned from the catheter (gastric $\mathrm{pH}$ indicates correct positioning), and/or radiograph. RESULTS: The group's median age was 3 years (range $4 \mathrm{~d}$ to $16 \mathrm{y})$. All 20 patients had successful gastric catheter placement. The $\mathbf{E A}_{\mathrm{di}}$ catheter provided characteristic patterns for correctly placed tubes, tubes malpositioned above or below the gastroesophageal junction, and curled tubes. Proper catheter position was confirmed via radiograph and/or gastric $\mathbf{p H}$ in all 20 patients. CONCLUSIONS: $\mathrm{EA}_{\mathrm{di}}$ guidance helps confirm proper gastric catheter position, is equivalent to our standard practice for confirming gastric catheter placement, and may reduce the need for radiographs and improve patient safety by avoiding catheter malpositions. Key words: neurally adjusted ventilatory assist; NAVA; pediatric; nasogastric tube; enteral feeding tubes; enteral nutrition; catheter malposition. [Respir Care 2011;56(4):467-471. (C) 2011 Daedalus Enterprises]
\end{abstract}

\section{Introduction}

Placement of a nasal or oral enteral tube, for feeding, medication administration, or gastric decompression, is one

At the time of this study, Brian K Walsh RRT-NPS was affiliated with the Department of Respiratory Care, Children's Hospital Boston, Boston, Massachusetts. He is now affiliated with the Respiratory Care Department, Children's Medical Center, Dallas, Texas. At the time of this study Michael L Green MD was affiliated with the Division of Critical Care Medicine, Children's Hospital, Boston, Boston, Massachusetts. He is now affiliated with the Critical Care Division, University of Texas Southwestern University, and with the Children's Medical Center, Dallas, Texas Gerhard K Wolf MD and John H Arnold MD are affiliated with the of the most frequently performed procedures in critically ill children. ${ }^{1}$ A key component of tube placement is confirming proper tube position. The incidence of improper

Division of Critical Care Medicine, Children's Hospital Boston, Boston, Massachusetts.

The authors have disclosed a relationship with Maquet Critical Care, which provided the catheters used in this study.

Correspondence: Brian K Walsh RRT-NPS, Respiratory Care Department, C6306, Children's Medical Center, 1935 Medical District Drive, Dallas TX 75235. E-mail: brian.walsh@childrens.com.

DOI: $10.4187 /$ respcare. 00886 


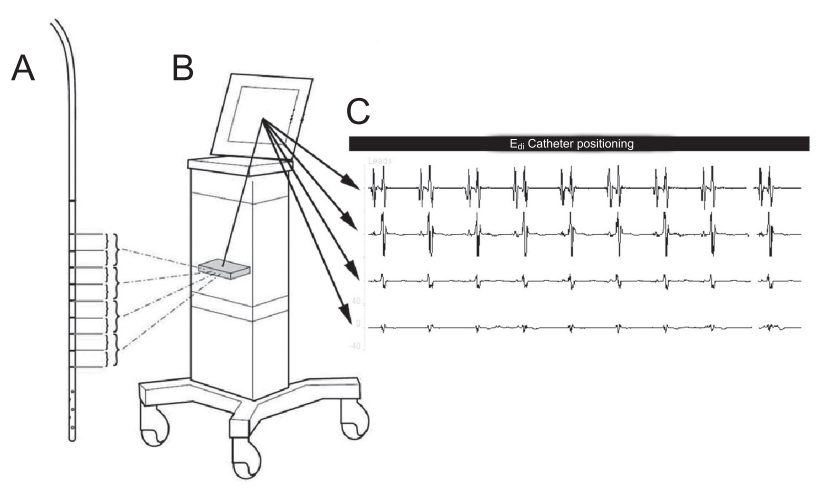

Fig. 1. Catheter, ventilator, and example of the waveforms of the electrical activity of the diaphragm $\left(E A_{d i}\right)$ in neurally adjusted ventilatory assist (NAVA) ventilation. The $E A_{d i}$ catheter $(A)$ has 9 electrodes, the signals from which are filtered down to 4 waveforms, which are transmitted to the ventilator $(\mathrm{B})$, and displayed on the catheter-positioning screen (C).

tube position during placement is reported to be as high as $20-43.5 \%$ in pediatric patients. ${ }^{1-3}$ Methods to confirm proper tube placement include suctioning fluid from the tube and checking the fluid for gastric $\mathrm{pH}$, auscultation over the stomach while air is injected into the tube, capnometry, and radiograph. ${ }^{4-7}$

A new mode of mechanical ventilation, neurally adjusted ventilatory assist (NAVA, available only on the Servo-i ventilator, Maquet Critical Care, Solna, Sweden) requires a proprietary-design catheter (Maquet Critical Care, Solna, Sweden) embedded with 9 electrodes that detect the electrical activity of the diaphragm $\left(\mathrm{EA}_{\mathrm{di}}\right)$. NAVA uses the $\mathrm{EA}_{\mathrm{di}}$ signal to deliver assisted ventilation in proportion to and in synchrony with that activity (Fig. 1). ${ }^{8}$ Recent trials found that NAVA improved patient-ventilator synchrony and reduced airway pressure in mechanically ventilated pediatric patients. ${ }^{9}$ To properly control NAVA, the $\mathrm{EA}_{\mathrm{di}}$ catheter electrodes must be positioned at the level of the crura of the diaphragm. When properly positioned, the $\mathrm{EA}_{\mathrm{di}}$ catheter tip lies within the stomach, and the electrodes align within the area of the diaphragm. To confirm proper placement the practitioner relies on the $\mathrm{EA}_{\mathrm{di}}$ waveforms on the catheter-positioning screen on the ventilator (see Fig. 1). We studied $\mathrm{EA}_{\mathrm{di}}$ guidance as an immediate, real-time confirmation of proper gastric tube placement in mechanically ventilated pediatric patients.

\section{Methods}

This study was part of a larger study ${ }^{10}$ on electrical activity of the diaphragm during extubation-readiness testing of intubated pediatric patients, in a 29-bed pediatric intensive care unit (ICU) in a tertiary-care pediatric hospital. The study was approved by our institutional review board, and written informed consent was obtained from all the patients' parents or guardian. A core group of nurses and respiratory therapists from the ICU had been trained in the proper positioning and maintenance of the $\mathrm{EA}_{\mathrm{di}}$ catheter, and only those with this training were involved with the catheter placements.

All the patients were intubated and mechanically ventilated at the time of enrollment. Study patients were transitioned onto the Servo-i ventilator. An appropriate-size EA $_{\mathrm{di}}$ catheter was selected based on the patient's weight and the nurse's preference. Per the manufacturer's recommendation, we estimated the proper catheter insertion distance based on the measured distance from the nose to the ear to the xiphoid process (NEX) with each patient. ${ }^{11} \mathrm{We}$ immersed the catheter's distal end in water for $5 \mathrm{~min}$ prior to insertion, to activate the self-lubricant embedded on the catheter. We conducted the NAVA module self-check, which shows $4 \mathrm{EA}_{\mathrm{di}}$ waveforms on the catheter-positioning screen, which correspond to 4 levels near the catheter's distal end. We then attached the proximal end of the tube to the ventilator module and inserted the catheter either orally or nasally, depending on the clinical indication and judgment per our current practice. We used NEX as an estimate of where the tube should be initially placed.

As the $\mathrm{EA}_{\mathrm{di}}$ catheter was advanced, the respiratory therapist viewed the $\mathrm{EA}_{\mathrm{di}}$ waveforms on the catheter-positioning screen, including the atrial signal as the tube passed posterior to the heart. When the catheter tip reached the proper position in the stomach, the lower $\mathrm{EA}_{\mathrm{di}}$ waveforms lost the atrial signal (ie, no $\mathrm{P}$ waves) (Fig. 2), and the ventilator reported an $\mathrm{EA}_{\mathrm{di}}$ waveform. Proper $\mathrm{EA}_{\mathrm{di}}$ catheter placement was defined as: (1) no $\mathrm{P}$ waves in the distal waveform, (2) a decrease in overall voltage distally, and (3) correct highlighting (blue on the catheter-positioning screen) of the middle $2 \mathrm{EA}_{\mathrm{di}}$ waveforms. Occasionally a short $(<2 \mathrm{~s})$ expiratory hold was required to encourage diaphragm contraction in over-ventilated patients.

After correct catheter positioning was indicated by the NAVA catheter-positioning screen, each patient had initial confirmation of catheter position according to our unit protocol, which is auscultation over the stomach while air is injected into the catheter, followed by suctioning of fluid from the catheter and checking that fluid's $\mathrm{pH}$ (which should be $\leq 5$ ). If no fluid is obtained or the fluid does not have gastric $\mathrm{pH}$, an immediate radiograph is obtained. All the patients had proper tube position reconfirmed via routine chest radiograph within 24 hours of initial tube placement.

\section{Results}

Table 1 describes the 20 subjects, who underwent a total of 23 catheter placements. Their median age was 3 y (range $4 \mathrm{~d}$ to $16 \mathrm{y}$ ). Their mean weight was $25.9 \mathrm{~kg}$ (range 3-80 kg). The most common etiologies contributing to the 

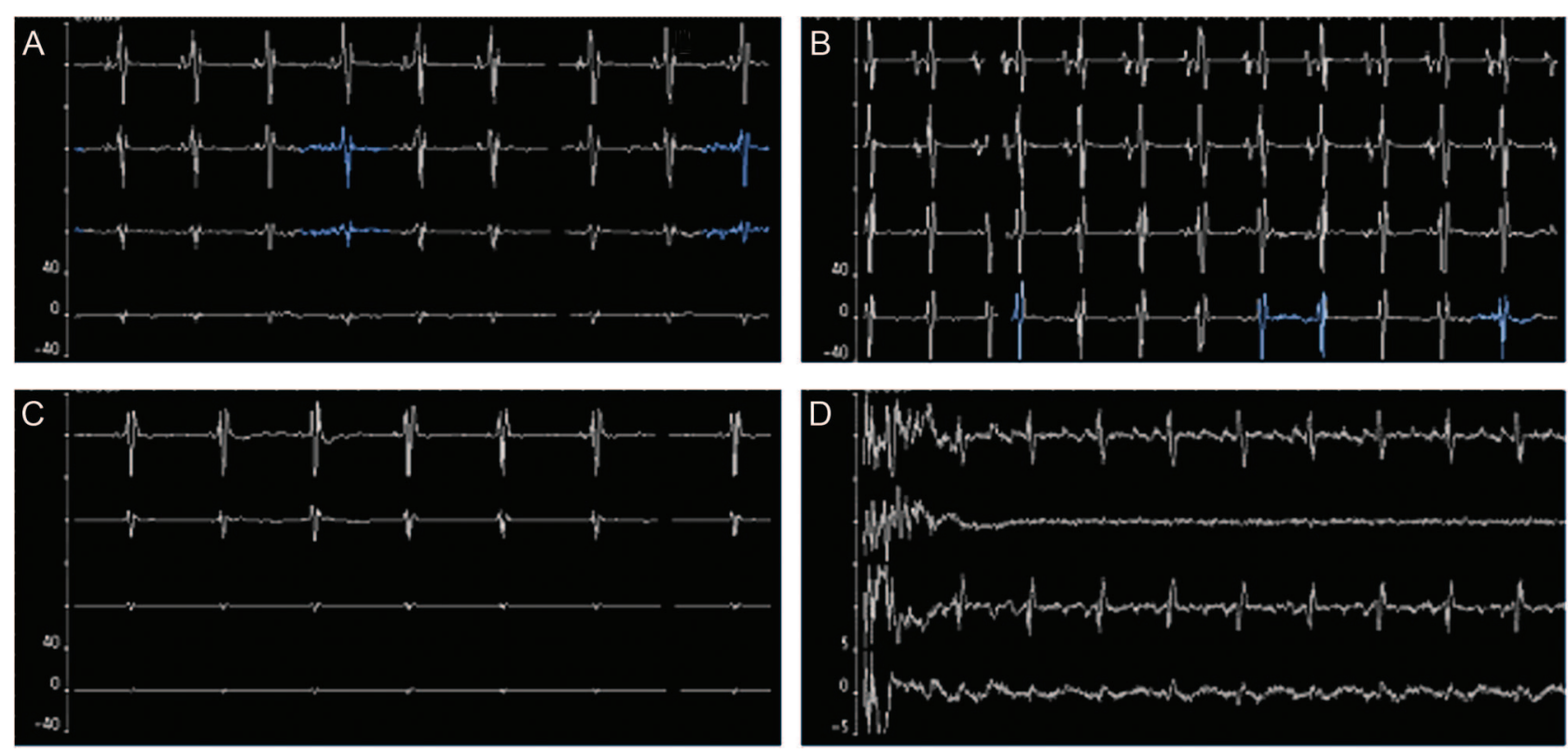

Fig. 2. Electrical activity of the diaphragm $\left(E A_{d i}\right)$ waveforms from the $E A_{d i}$ catheter of the neurally adjusted ventilatory assist (NAVA) ventilation system. A: Proper catheter positioning in the stomach is indicated by the absence of $P$ waves in the bottom $E A_{d i}$ waveform. $\mathrm{B}$ : The catheter is too far cephalad (above the gastroesophageal junction), indicated by the presence of $P$ waves in all 4 EA $A_{d i}$ waveforms. C: The catheter is too far caudal (below the gastroesophageal junction), indicated by the absence of $P$ waves in all 4 EA $A_{d i}$ waveforms. D: The catheter is curled, indicated by 2 identical $\mathrm{EA}_{\mathrm{di}}$ waveforms with a decreased-voltage waveform in between.

need for mechanical ventilation were acute respiratory distress syndrome and infectious etiologies ( 14 of the 20 patients). Two patients were neonates with congenital diaphragmatic hernia.

All 20 patients had successful gastric catheter placement with $\mathrm{EA}_{\mathrm{di}}$ guidance. Eighteen catheter placements were confirmed via gastric $\mathrm{pH}$, and 5 were confirmed via radiograph because no gastric fluid was obtained. With catheters whose position was initially confirmed via $\mathrm{pH}$, 18 of 18 subsequently had proper position confirmed via routine chest or abdominal radiograph within 24 hours of catheter placement.

In 3 patients the original $\mathrm{EA}_{\mathrm{di}}$ catheter was removed during the study period. Two patients had inadvertent catheter displacement, and those catheters were successfully replaced with $\mathrm{EA}_{\mathrm{di}}$ guidance. One patient had the catheter electively removed for a magnetic resonance imaging (MRI) study (the $\mathrm{EA}_{\mathrm{di}}$ catheter is not compatible with MRI), and the catheter was successfully replaced with $\mathrm{EA}_{\mathrm{di}}$ guidance.

In the process of placing the catheters, the $\mathrm{EA}_{\mathrm{di}}$ waveforms provided the characteristic patterns for $\mathrm{EA}_{\mathrm{di}}$ catheters that were either correct or in malposition above the gastroesophageal junction, below the gastroesophageal junction, or curled. If the distal end of the catheter terminated in the oropharynx or in the esophagus before its passage posterior to the heart, the waveforms showed a complete absence of cardiac electrical activity. If the catheter was advanced further but continued to remain high relative to the optimal position, then $\mathrm{P}$ waves persisted in all 4 waveforms (see Fig. 2B). In contrast, if the $\mathrm{EA}_{\mathrm{di}}$ catheter was advanced too distally, the $\mathrm{P}$ wave was absent from all of the waveforms (see Fig. 2C). If the catheter curled, 2 waveforms appeared identical, with a decreased voltage waveform in between (see Fig. 2D). There were no instances of tracheal catheter placement.

\section{Discussion}

In all 20 patients and all 23 catheter placements the catheter was correctly placed, as evidenced by the $\mathrm{EA}_{\mathrm{di}}$ waveforms and confirmed via gastric $\mathrm{pH}$ or radiograph. No catheters were placed in the trachea. The catheter placement success in this series was probably related to the ability to make real-time adjustments based on the $\mathrm{EA}_{\mathrm{di}}$ waveforms.

Methods to confirm proper gastric tube position include radiography, gastric $\mathrm{pH}$ of fluid suctioned from the tube, auscultation over the stomach while air is injected into the tube, fluoroscopy, and capnography. ${ }^{12-16}$ In our pediatric ICU, to confirm gastric placement the nursing staff rely on gastric $\mathrm{pH}$ and subsequent radiograph. In a previous study the gastric $\mathrm{pH}$ method was only $77 \%$ sensitive and $38 \%$ specific for proper placement. ${ }^{6}$ In an observational study of critically ill adults, the gastric $\mathrm{pH}$ method provided misinformation regarding tube placement in $64 \%$ of cases. ${ }^{17}$ Methods such as radiography and gastric fluid suctioning have the additional disadvantages of not providing realtime data. 


\section{Electrocardiographic Guidance for the Placement of Gastric Feeding Tubes}

Table 1. Subjects

\begin{tabular}{|c|c|c|c|c|c|c|c|}
\hline $\begin{array}{l}\text { Patient } \\
\text { No. }\end{array}$ & Sex & $\begin{array}{c}\text { Mechanical } \\
\text { Ventilation } \\
\text { Hours }\end{array}$ & Age & $\begin{array}{c}\text { NAVA } \\
\text { Catheter } \\
\text { Hours }\end{array}$ & $\begin{array}{l}\text { Weight } \\
(\mathrm{kg})\end{array}$ & Diagnoses & $\begin{array}{c}\text { Primary } \\
\text { Confirmation } \\
\text { of Gastric Tube } \\
\text { Placement }\end{array}$ \\
\hline 1 & F & 172 & $2 y$ & 42 & 11 & $\begin{array}{l}\text { Chromosomal abnormality, laryngomalacia, } \\
\text { respiratory failure }\end{array}$ & $\mathrm{pH}$ \\
\hline 2 & F & 469 & $5 y$ & 20 & 20 & $\begin{array}{l}\text { Trisomy } 21 \text {, seizure disorder, parainfluenza } \\
\text { pneumonia }\end{array}$ & $\mathrm{pH}$ \\
\hline 3 & F & 288 & $3 y$ & 48 & 14 & $\begin{array}{l}\text { Nephrotic syndrome, streptococcus } \\
\text { pneumonia, bacteremia, sepsis, ARDS }\end{array}$ & $\mathrm{pH}$ \\
\hline 4 & M & 92 & $2 \mathrm{mo}$ & 72 & 5 & $\begin{array}{l}\text { Respiratory syncytial virus, bronchiolitis, } \\
\text { membranous ventricular septal defect }\end{array}$ & $\mathrm{pH}$ \\
\hline 5 & M & 60 & $14 \mathrm{y}$ & 18 & 65 & MRSA pneumonia & Radiograph \\
\hline 6 & F & 250 & $7 y$ & 168 & 30 & MRSA pneumonia & $\mathrm{pH}$ \\
\hline 7 & F & 626 & $13 \mathrm{y}$ & 224 & 56 & Septic shock, ARDS & $\mathrm{pH}$ \\
\hline 8 & F & 153 & $11 \mathrm{y}$ & 48 & 57 & ARDS, seizure disorder, developmental delay & $\mathrm{pH}$ \\
\hline 9 & M & 86 & $1 \mathrm{y}$ & 24 & 10 & Foreign-body aspiration, pneumonia & $\mathrm{pH}$ \\
\hline 10 & M & 221 & $16 \mathrm{y}$ & 66 & 80 & Pulmonary contusion & $\mathrm{pH}$ \\
\hline 11 & $\mathrm{~F}$ & 302 & $8 \mathrm{mo}$ & 49 & 8 & H1N1 pneumonia, ARDS & $\mathrm{pH}$ \\
\hline 12 & $\mathrm{~F}$ & 489 & $1 \mathrm{y}$ & 48 & 8 & $\begin{array}{l}\text { Chronic lung disease, pulmonary } \\
\text { hypertension, myocarditis }\end{array}$ & $\mathrm{pH}$ \\
\hline 13 & M & 179 & $3 \mathrm{y}$ & 106 & 22 & H1N1 influenza & $\mathrm{pH}$ \\
\hline 14 & M & 72 & $6 y$ & 20 & 18 & Trisomy 21, pneumonia & $\mathrm{pH}$ \\
\hline 15 & M & 654 & $1 \mathrm{mo}$ & 336 & 3 & Congenital diaphragmatic hernia & Radiograph \\
\hline 16 & M & 100 & $3 \mathrm{y}$ & 72 & 15 & Guillain-Barré syndrome & $\mathrm{pH} \times 2$ \\
\hline 17 & M & 138 & $12 \mathrm{y}$ & 94 & 60 & Near drowning, ARDS & $\mathrm{pH} \times 2$ \\
\hline 18 & M & 30 & $4 \mathrm{~d}$ & 128 & 3 & Congenital diaphragmatic hernia & Radiograph $\times 2$ \\
\hline 19 & $\mathrm{~F}$ & 276 & $2 \mathrm{y}$ & 122 & 13 & H1N1 & $\mathrm{pH}$ \\
\hline 20 & $\begin{array}{c}\mathrm{F} \\
\mathrm{M} 50 \%\end{array}$ & $\begin{array}{c}134 \\
\text { Mean } 240 \mathrm{~h}\end{array}$ & $\begin{array}{c}9 \mathrm{y} \\
\text { Mean } 5.4 \mathrm{y}\end{array}$ & $\begin{array}{c}68 \\
\text { Mean } 89 \mathrm{~h}\end{array}$ & $\begin{array}{c}20 \\
\text { Mean } 26 \mathrm{~kg}\end{array}$ & Cardiac arrest, aspiration pneumonia & $\begin{array}{l}\text { Radiograph } \\
\mathrm{pH} 78 \%\end{array}$ \\
\hline
\end{tabular}

ARDS $=$ acute respiratory distress syndrome

MRSA $=$ methicillin-resistant Staphylococcus aureus

The inadvertent placement of a gastric tube in the trachea contributes most substantially to the morbidities associated with tube misplacement, including instillation of food into the trachea, tracheal perforation, pneumothorax, and pulmonary hemorrhage. ${ }^{18-21}$ Factors associated with errors in enteral tube placement in children include younger age, decreased level of consciousness, abdominal distention, presence of emesis, and the use of the orogastric route. ${ }^{1}$ The $\mathrm{EA}_{\mathrm{di}}$ waveforms can immediately notify the clinician that the tube is not in the esophagus/stomach and may be in the trachea. In the trachea the catheter would not pass posterior to the right atrium, because the carina is cranial to the right atrium, so no cardiac signal would be detected, which indicates misplacement.

Previous investigators have used ECG for positioning gastric catheters in adults. In critically ill patients, Diaz-Rodriguez et $\mathrm{al}^{22}$ used a standard nasoenteric tube, into which they placed an ECG lead. They placed other leads on the abdomen, and identified a characteristic ECG pattern that confirmed gastric placement in 95 of the 100 patients in the study. ${ }^{22}$
Another recent study, with 25 adult patients, compared NEX-guided placement to $\mathrm{EA}_{\mathrm{di}^{-}}$-guided placement. ${ }^{11}$ They evaluated the utility of NEX in approximating optimal catheter position with the distal end in the stomach, and in $72 \%$ of the patients they obtained correct catheter position with NEX alone. ${ }^{11}$ With EA $_{\mathrm{di}}$-guided placement, all the patients had optimal catheter placement. The median difference between the positions obtained with NEX versus $\mathrm{EA}_{\mathrm{di}}$ catheter was $2 \mathrm{~cm}$, though that difference ranged from $3 \mathrm{~cm}$ too cranial to $12 \mathrm{~cm}$ too caudal. Though that study evaluated optimal catheter position to assure proper functioning of NAVA, and did not examine feeding-tube position, the study highlights the considerable variability in catheter positioning with NEX alone. In that adult population, $\mathrm{EA}_{\mathrm{di}}$ guidance provided more accurate placement. The differences between the estimated tube-insertion depth and the depth as determined with $\mathrm{EA}_{\mathrm{di}}$ guidance in that adult population are potentially of greater relative magnitude in infants and children, because of their smaller size.

We did not compare the initial NEX measurement to the catheter depth obtained with $\mathrm{EA}_{\mathrm{di}}$ guidance. With the knowl- 


\section{Electrocardiographic Guidance for the Placement of Gastric Feeding Tubes}

edge that the NEX method involves substantial variability in tube positioning, we used NEX only as a starting point, and subsequently made adjustments based on the $\mathrm{EA}_{\mathrm{di}}$ waveforms. A critical component of our study was to determine whether the portion of the feeding tube distal to the electrodes is the proper length to allow the distal end of the tube to rest in the stomach. In our 23 catheter placements we found that, using the proper size tube and the $\mathrm{EA}_{\mathrm{di}}$ waveforms, we were able to reliably place the tube in the stomach.

\section{Limitations}

To our knowledge, our series is the first to describe the use of $\mathrm{EA}_{\mathrm{di}}$ to aid in enteral tube placement in critically ill children. Because this study is a case series, it lacks a control group of patients who received only the usual means of verification of tube placement. We conducted a relatively small number of catheter placements, and a larger number of catheter placements might have included some misplacements. Also, since this series describes the experience at only one center, with a multidisciplinary team well oriented to the use of NAVA and proper EA $_{\mathrm{di}}$ catheter placement, the results at other centers with different team compositions and levels of expertise might differ. In our pediatric ICU we rely on a core group of respiratory therapists and nurses with expertise in placing EA $_{\mathrm{di}}$ catheters. More experience using $\mathrm{EA}_{\mathrm{di}}$ catheters in this manner at other centers is necessary before fully understanding the generalizability of our findings. Our series lacked blinding of the practitioners who placed the tubes, which adds the potential for bias. Finally, one major impediment to the general use of the $\mathrm{EA}_{\mathrm{di}}$ catheter to verify gastric tube position is the cost of the catheter $(\$ 180)$, which is much more than a regular feeding catheter. In addition, the $\mathrm{EA}_{\mathrm{di}}$ catheter requires a Servo-i ventilator equipped with NAVA.

\section{Conclusions}

Despite the limitations, we believe this case series highlights a novel method of confirming proper gastric tube placement that is equivalent to standard care in critically ill pediatric patients, and might improve patient safety by avoiding gastric tube malpositions. Further study of its use, including a trial comparing it to the current standard of care, along with an examination of the overall cost of the EA $_{\mathrm{di}}$ catheter compared to the cost of fewer chest radiographs, should be performed before this technology can be recommended as a routine means of confirming gastric tube placement.

\section{ACKNOWLEDGMENTS}

We thank Sue Hamilton-Bruno RN and Mary-Jeanne Manning RN for their help and expertise in placing the NAVA catheters.

\section{REFERENCES}

1. Ellett ML, Maahs J, Forsee S. Prevalence of feeding tube placement errors \& associated risk factors in children. MCN Am J Matern Child Nurs 1998;23(5):234-239.

2. Ellett ML. What is known about methods of correctly placing gastric tubes in adults and children. Gastroenterol Nurs 2004;27(6):253-259.

3. Ellett ML, Beckstrand J. Examination of gavage tube placement in children. J Soc Pediatr Nurs 1999;4(2):51-60.

4. Huffman S, Pieper P, Jarczyk KS, Bayne A, O'Brien E. Methods to confirm feeding tube placement: application of research in practice. Pediatr Nurs 2004;30(1):10-13.

5. Burns SM, Carpenter R, Truwit JD. Report on the development of a procedure to prevent placement of feeding tubes into the lungs using end-tidal $\mathrm{CO}_{2}$ measurements. Crit Care Med 2001;29(5):936-939.

6. Seguin P, Le Bouquin V, Aguillon D, Maurice A, Laviolle B, Malledant Y. [Testing nasogastric tube placement: evaluation of three different methods in intensive care unit.] Ann Fr Anesth Reanim 2005;24(6):594-599. Article in French.

7. Metheny N. Minimizing respiratory complications of nasoenteric tube feedings: state of the science. Heart Lung 1993;22(3):213-223.

8. Sinderby C. Neurally adjusted ventilatory assist (NAVA). Minerva Anestesiol 2002;68(5):378-380.

9. Bengtsson JA, Edberg KE. Neurally adjusted ventilatory assist in children: an observational study. Pediatr Crit Care Med;11(2):253-257.

10. Wolf GK, Walsh BK, Green ML, Arnold JH. Electrical activity of the diaphragm during extubation readiness testing in critically ill children. Pediatr Crit Care Med. Nov 4. [Epub ahead of print].

11. Barwing J, Ambold M, Linden N, Quintel M, Moerer O. Evaluation of the catheter positioning for neurally adjusted ventilatory assist. Intensive Care Med 2009;35(10):1809-1814.

12. Stock A, Gilbertson H, Babl FE. Confirming nasogastric tube position in the emergency department: $\mathrm{pH}$ testing is reliable. Pediatr Emerg Care 2008;24(12):805-809.

13. Ellett ML, Woodruff KA, Stewart DL. The use of carbon dioxide monitoring to determine orogastric tube placement in premature infants: a pilot study. Gastroenterol Nurs 2007;30(6):414-417.

14. Elpern EH, Killeen K, Talla E, Perez G, Gurka D. Capnometry and air insufflation for assessing initial placement of gastric tubes. Am J Crit Care 2007;16(6):544-549.

15. Nyqvist KH, Sorell A, Ewald U. Litmus tests for verification of feeding tube location in infants: evaluation of their clinical use. J Clin Nurs 2005;14(4):486-495.

16. Huerta G, Puri VK. Nasoenteric feeding tubes in critically ill patients (fluoroscopy versus blind). Nutrition 2000;16(4):264-267.

17. Conner TM, Carver D. The role of gastric $\mathrm{pH}$ testing with small-bore feeding tubes: in the intensive care unit. Dimens Crit Care Nurs 2005;24(5):210-214.

18. Miller KS, Tomlinson JR, Sahn SA. Pleuropulmonary complications of enteral tube feedings: two reports, review of the literature, and recommendations. Chest 1985;88(2):230-233.

19. Creel AM, Winkler MK. Oral and nasal enteral tube placement errors and complications in a pediatric intensive care unit. Pediatr Crit Care Med 2007;8(2):161-164.

20. el-Gamel A, Watson DC. Transbronchial intubation of the right pleural space: a rare complication of nasogastric intubation with a polyvinylchloride tube: a case study. Heart Lung 1993;22(3):224-225.

21. Metheny NA, Meert KL, Clouse RE. Complications related to feeding tube placement. Curr Opin Gastroenterol 2007;23(2):178-182.

22. Diaz-Rodriguez A, Esponda-Prado J, Ize-Lamache L. [Placement of nasoenteral feeding tubes under electrocardiographic guidance in critically ill patients.] Cir Cir 2004;72(2):85-88. 